\title{
ESQUIZOFRENIA: QUARENTA ANOS DA HIPÓTESE DOPAMINÉRGICA SOB A ÓTICA DA QUÍMICA MEDICINAL
}

\section{Ricardo Menegatti}

Instituto de Química, Universidade Federal do Rio de Janeiro, 21949-900, Rio de Janeiro - RJ

Carlos Alberto Manssour Fraga* e Eliezer J. Barreiro

Faculdade de Farmácia, Universidade Federal do Rio de Janeiro, CP 68006, 21944-970 Rio de Janeiro - RJ

Vera Lucia Eifler Lima, Stela Maris Kuze Rates e Teresa Dalla Costa

Faculdade de Farmácia, Universidade Federal do Rio Grande do Sul, 90610-000 Porto Alegre - RS

Recebido em 8/4/03; aceito em 27/8/03

\begin{abstract}
SCHIZOPHRENIA: FORTY YEARS OF THE DOPAMINERGIC HYPOTHESIS FROM THE MEDICINAL CHEMISTRY
POINT OF VIEW. Schizophrenia is a devastating psychiatric illness that affects $1-2 \%$ of the world population and continues as a challenge to neuroscience. In this work, we describe an account about the historical evolution of the dopaminergic hypothesis of schizophrenia discussing, from the medicinal chemistry point of view all different classes of antipsychotic drugs, emphasizing the rational design, structure activity relationships (SAR) and physico-chemical properties related with its molecular mechanism of action.
\end{abstract}

Keywords: schizophrenia; antipsychotic drugs; dopamine receptor ligands.

\section{INTRODUÇÃO}

A esquizofrenia é uma patologia do sistema nervoso central (SNC) que incide sobre $c a$. 1-2\% da população mundial, cuja distribuição independe de sexo, idade, raça e nível sócio-econômico, representando enorme desafio à neurociência ${ }^{1}$. Estudos com familiares e gêmeos esquizofrênicos apontam para existência de componentes genéticos na etiologia da esquizofrenia ${ }^{2}$ e, recentemente, identificou-se o envolvimento de vários genes que codificam proteínas da matriz sináptica na gênese desta doença ${ }^{3}$.

O termo esquizofrenia foi cunhado em 1908 pelo médico suíço Eugen Bleuler (1857-1939), até quando este quadro patológico foi denominado dementia paecox. Este notável psiquiatra à época definiu esquizofrenia como um distúrbio associativo, divergindo da visão inicial que a considerava um dano cerebral irreversível ${ }^{4,5}$. Prova viva desta definição é o matemático John Forbes Nash Jr. (Nobel em Economia, 1994) o qual teve sua vida retratada no filme "A Beautiful Mind", que logrou o Oscar de melhor filme e diretor, em 2002.

Embora a etiologia da esquizofrenia ainda não seja completamente conhecida, hoje a doença é considerada consequiência de diversos distúrbios do $\mathrm{SNC}^{1,6}$. Desta forma, diversas hipóteses envolvendo dopamina ${ }^{7}$, serotonina ${ }^{8}$, glutamato ${ }^{9}$, neuropeptídeos ${ }^{10,11}$, ligantes de receptores muscarínicos ${ }^{12}$, adenosina ${ }^{13}$, sítios de ligação sigma ${ }^{14} \mathrm{e}$ fosfolipase $\mathrm{A} 2^{15}$ têm sido propostas na tentativa de melhor compreender a fisiopatologia da doença. O aumento da atividade da fosfolipase A2 no cérebro de esquizofrênicos vem sendo estudado pelo Dr. W. F. Gattaz, principal expoente em esquizofrenia no Brasil. Esta enzima metaboliza fosfolipídeos de membrana a ácidos graxos e produtos citotóxicos como lisofosfatidilcolina, desempenhando importante papel na modulação dos constituintes de membranas celulares ${ }^{15}$.

A complexidade e ausência de sintomas comuns a todos os pacientes esquizofrênicos têm dificultado a compreensão da doença e a

*e-mail: cmfraga@pharma.ufrj.br

LASSBio: URL: http:\|www.farmacia.ufrj.brllassbio eleição de um alvo-terapêutico único que viabilize, pelo emprego de estratégias da Química Medicinal, a descoberta de novos fármacos mais efetivos do que aqueles atualmente empregados ${ }^{16}$ (Figura 1).

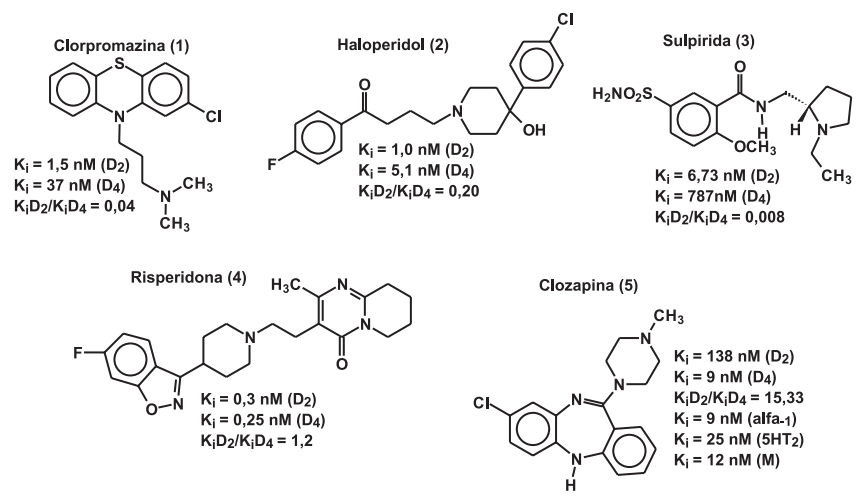

Figura 1. Fármacos antipsicóticos típicos 1-3 e atípicos 4-5 utilizados no tratamento da esquizofrenia

Os antipsicóticos clássicos como clorpromazina (1), haloperidol (2) e (-)-(S)-sulpirida (3), empregados no tratamento da esquizofrenia, apresentam como principal característica uma maior afinidade pelo receptor dopaminérgico $\mathrm{D}_{2}$, em relação ao receptor $\mathrm{D}_{4}^{1,16}$, como pode ser observado através da análise comparativa dos valores de constantes de inibição $\left(\mathrm{K}_{\mathrm{i}}\right)$ para ambos os sub-tipos de receptores ${ }^{1,16}$ (Figura 1). A maior afinidade dos antipsicóticos clássicos pelos receptores $D_{2}$ agrega, aos efeitos terapêuticos desejados, efeitos colaterais, e.g. extrapiramidais (EPS), principal inconveniente do emprego desta classe de fármacos ${ }^{16}$. Por outro lado, antipsicóticos atípicos como risperidona (4) e clozapina (5) possuem maior afinidade pelo receptor $\mathrm{D}_{4}$ em relação ao receptor $\mathrm{D}_{2}$. Por conseguinte, apresentam menor tendência de induzirem EPS ${ }^{16,17}$. Como conseqüência do distinto perfil dos antipsicóticos clássicos e atípicos, houve significativo incremento nos estudos envolvendo o receptor $\mathrm{D}_{4}$ a partir do início da década de 90 , 
visando a descoberta de novos candidatos a protótipos de agentes antipsicóticos que apresentassem maior eficácia e segurança.

De modo geral, em um quadro esquizofrênico típico as funções cognitivas e emocionais encontram-se alteradas em função de modificações da resposta dopaminérgica ${ }^{16}$. Essas alterações, por sua vez, podem ser divididas em dois subgrupos de sintomas: os positivos e os negativos. Postula-se que os sintomas positivos, como ilusões, alucinações, psicoses, paranóias, pensamentos desordenados e fala desorganizada, ocorram devido à hiperatividade dopaminérgica na área mesolímbica do cérebro de pacientes esquizofrênicos ${ }^{18}$. Por outro lado, hipoatividade dopaminérgica na mesma região é associada à doença de Parkinson. Já os sintomas negativos, como a desmotivação, comportamento emocional violento, isolamento social, deficiência cognitiva e fala lenta, seriam oriundos de uma hipoatividade dopaminérgica nas projeções do cortéx pré-frontal ${ }^{18,19}$.

\section{Antipsicóticos clássicos (ou neurolépticos)}

Em meados da década de 50, foram introduzidos para o tratamento da esquizofrenia os fármacos fenotiazínicos, antipsicóticos clássicos que representaram um marco na farmacoterapia psiquiátrica, melhorando consideravelmente o prognóstico desta e de outras patologias do sistema nervoso central (SNC) ${ }^{20}$, outrora tratadas pelo procedimento cirúrgico conhecido como lobotomia ${ }^{21}$. O principal representante desta classe de substâncias é a clorpromazina (1), primeiro fármaco a tratar efetivamente os sintomas positivos da esquizofrenia, sendo ainda capaz de reduzir o tempo médio de hospitalização de pacientes esquizofrênicos e as recidivas de internações ${ }^{16}$.

Por outro lado, o emprego terapêutico de derivados fenotiazínicos não leva à melhora dos sintomas negativos, nem da deficiência cognitiva dos pacientes esquizofrênicos. Além disso, $c a$. 5-25\% destes pacientes mostraram-se refratários ao tratamento e outros 5-10\% foram intolerantes ao mesmo. Os antipsicóticos clássicos causam ainda hiperprolactinemia, desordem decorrente do aumento da secreção de prolactina, causada pelo bloqueio excessivo de receptores dopaminérgicos do subtipo $\mathrm{D}_{2}$ na glândula pituitária ${ }^{16}$.

Dentre os principais efeitos colaterais associados ao tratamento com antipsicóticos clássicos, incluem-se aqueles denominados sintomas Parkinsonianos (tremor, rigidez e bradicinesia), acatisia, distonia e discinesia tardia. Os sintomas Parkinsonianos são decorrentes de uma hipoatividade dopaminérgica na região nigroestriatal, oriunda do bloqueio de receptores dopaminérgicos do sub-tipo $\mathrm{D}_{2}$ pós-sinápticos pelos antipsicóticos clássicos. Em última análise, esse quadro mimetiza uma atividade hipo-dopaminérgica, que resulta em efeitos colaterais indesejados, como efeitos extrapiramidais. Atualmente, cogita-se que os efeitos extrapiramidais sejam originados do bloqueio excessivo de receptores dopaminérgicos do subtipo $\mathrm{D}_{2}$ na região do estriado, região cerebral responsável pelo controle da atividade motora fina ${ }^{16}$.

Posteriormente, outras classes de antipsicóticos clássicos foram emergindo como as butirofenonas ${ }^{22}$, e.g. haloperidol (2), as benzamidas $^{23}$, e.g. sulpirida (3) (Figura 1) e os tioxantenos ${ }^{24}$, e.g. clorprotixeno (7) (Figura 2), entre outros. Entretanto, estas novas classes de antipsicóticos clássicos não representaram significativa inovação em relação ao tratamento com os fenotiazínicos, e.g. 1, por não apresentaram espectro de ação muito superior aos mesmos ${ }^{16}$. O clorprotixeno (7), um bioisóstero conformacionalmente restrito de $\mathbf{1}$ (Figura 2), foi o primeiro fármaco da classe a chamar a atenção para a importância de fatores conformacionais $v s$ configuracionais, uma vez que seu isômero $Z$ é várias vezes mais ativo que o correspondente diastereoisômero $E^{20}$. Curiosamente, as orientações da cadeia alquilamina nas estruturas cristalográficas da clorpromazina (1) e do
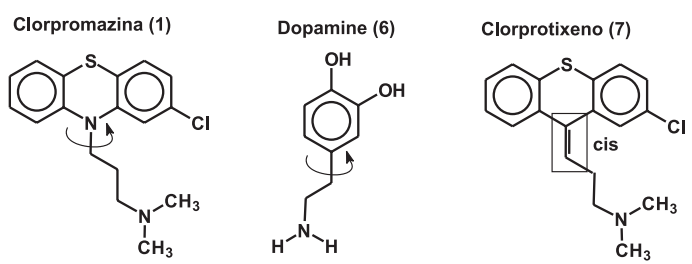

Figura 2. Gênese dos derivados tioxantênicos 7

diastereoisômero $Z$ de 7 são bastante semelhantes, imitando a conformação bioativa da dopamina (6), como será visto adiante (Figura 8).

\section{Antipsicóticos atípicos}

Na busca de novos agentes antipsicóticos mais efetivos que aqueles classicamente empregados no tratamento da esquizofrenia, i.e. 13, com menores efeitos colaterais e efeitos extrapiramidais, pesquisadores da Sandoz descobriram a clozapina $(\mathbf{5})^{25}$ (Figura 1 ), em meados da década de 60. A clozapina (5) é um fármaco multireceptor, que apresenta muitas vantagens em relação aos antipsicóticos 1-3 disponíveis até então, sendo efetiva no tratamento dos sintomas positivos e, parcialmente, sobre os sintomas negativos e a deficiência cognitiva dos esquizofrênicos. A clozapina (5) também mostrou-se capaz de prevenir psicoses em pacientes refratários e intolerantes aos antipsicóticos clássicos ${ }^{16}$. Em comparação aos fenotiazínicos e outros antipsicóticos clássicos, $\mathbf{5}$ provoca menos hiperprolactinemia e efeitos extrapiramidais, o que lhe conferiu a denominação de antipsicótico atípico. Contudo, o principal inconveniente no tratamento com a clozapina (5) reside na agranulocitose provocada em ca. 1-2\% dos pacientes ${ }^{26}$. Atualmente, nos Estados Unidos, o tratamento da esquizofrenia continua sendo realizado com os antipsicóticos clássicos 1-3, sendo a clozapina (5) administrada apenas a pacientes que se mostram intolerantes ou refratários ao tratamento convencional.

\section{RECEPTORES DOPAMINÉRGICOS}

\section{Análise conformacional da dopamina (6)}

Reconhecendo-se que a dopamina (6) é o agonista endógeno dos cinco sub-tipos de receptores dopaminérgicos conhecidos $\left(\mathrm{K}_{\mathrm{D}}=2,5\right.$ $\mathrm{nM}, \mathrm{D}_{1}{ }^{27-30} ; \mathrm{K}_{\mathrm{i}}=474 \mathrm{nM}, \mathrm{D}_{2}{ }^{31} ; \mathrm{K}_{\mathrm{i}}=25 \mathrm{nM}, \mathrm{D}_{3}{ }^{32} ; \mathrm{K}_{\mathrm{i}}=28 \mathrm{nM}, \mathrm{D}_{4}{ }^{33} \mathrm{e}$ $\mathrm{K}_{\mathrm{i}}=228 \mathrm{nM}, \mathrm{D}_{5}{ }^{34}$ ), pode-se admitir que a afinidade e o reconhecimento molecular pelos diversos sub-tipos de receptores seja reflexo de sua flexibilidade conformacional ${ }^{35}$.

Na Figura 3 encontram-se apresentadas na projeção de Newman as principais conformações da dopamina (6): antiperiplanar (2A) com ângulo diedro $(\theta)$ de $180^{\circ}$; - anticlinal (-ac) (2B) $\operatorname{com} \theta$ de $120^{\circ}$; sinclinal (-sin) (2C) $\operatorname{com} \theta$ de $60^{\circ}$; sinperiplanar (2D) que apresenta um ângulo diedro de $0^{\circ} ;+\operatorname{sinclinal}(+\sin )(\mathbf{2 E}) \operatorname{com} \theta$ de $60^{\circ} ;+$ anticlinal (+ac) (2F) com $\theta$ de $120^{\circ}{ }^{35-37}$.

Adicionalmente, a análise conformacional de $\mathbf{6}$ indica que, devido à dissimetria da subunidade catecólica, há dois possíveis rotâmeros, denominados $\alpha$ - e $\beta$-, ilustrados na Figura 4, para as conformações anticlinal (3A-B), antiperiplanar (3C-D), sinclinal (3E-F) e sinperiplanar (3G-H), os quais ampliam o elenco de arranjos espaciais adotados pela dopamina $(\mathbf{6})^{35-37}$.

Desta forma, pode-se contabilizar mais de dez conformações distintas para 6, que podem contribuir para diferentes formas de reconhecimento molecular para um ou mais sub-tipos de receptores dopaminérgicos ${ }^{35-37}$. Curiosamente, o mesmo resultado pode ser encontrado pela análise conformacional de outros neurotransmissores 


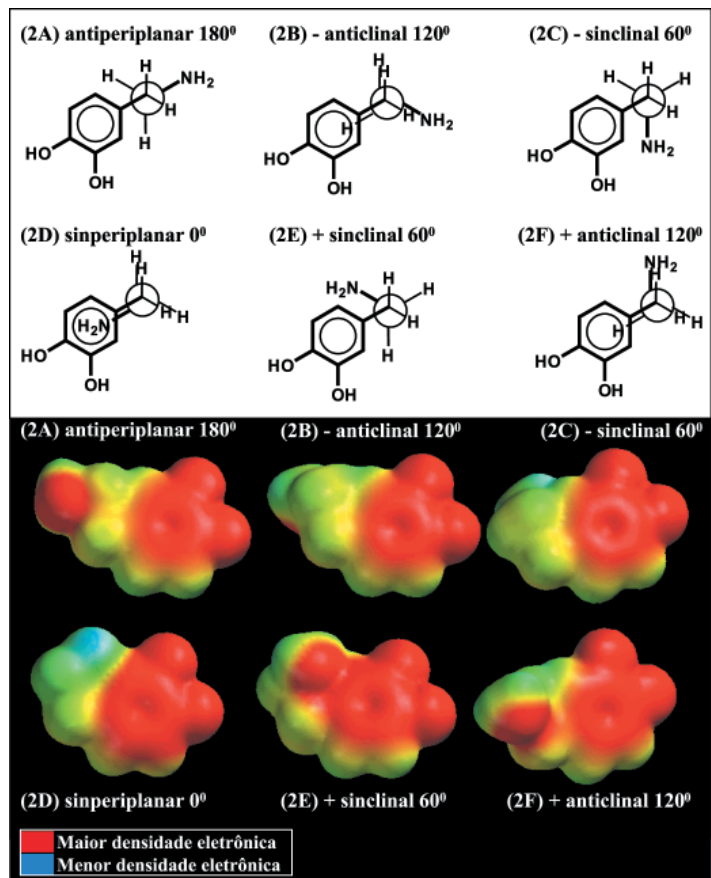

Figura 3. Principais conformações (2A-F) adotadas pela dopamina (6), segundo projeções de Newman, seguida de mapas de potencial eletrostático (2A-F), obtidos usando o método semiempírico AM1 no programa SpartanPro 1.0.5
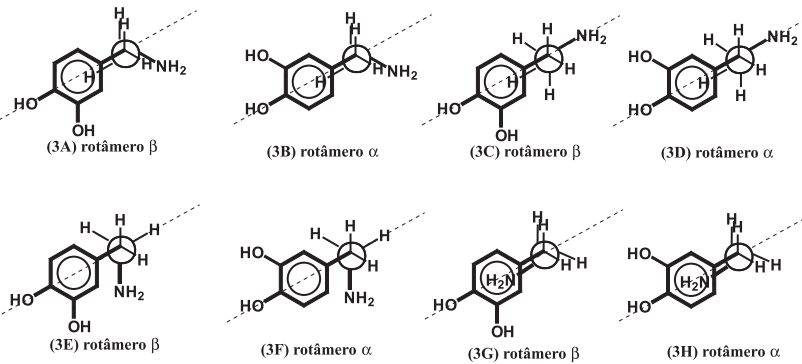

Figura 4. Rotâmeros (3A-H) da dopamina (6)

catecolamínicos que, coincidentemente, possuem diversos subtipos de receptores ${ }^{35-37}$.

Na Tabela 1 são apresentados a variação de energia, distância interatômica (N-ArOH meta) e descritores físico-químicos (momento dipolo e volume) calculados teoricamente, empregando o método semiempírico AM1 no programa Spartan 1.0.5 (Wavefunction, CA), em função da conformação adotada pela dopamina $(\mathbf{6})^{37}$ e na Figura 3 observa-se o mapa de potencial eletrostático das diversas conformações de $\mathbf{6}$ usando o mesmo método.
Em acordo com dados descritos na literatura ${ }^{35,38}$, observa-se que a conformação antiperiplanar (2A) é a mais estável, enquanto que a sinperiplanar (2D) é a menos estável. A ordem de estabilidade para as duas conformações (2A e D) pode ser observada tanto em termos de energia $(\sim 5 \mathrm{Kcal} / \mathrm{mol})$, bem como pela variação do momento dipolo $(\mu)$ em cerca de duas unidades, provavelmente devido à diferente orientação dos vetores, como mostram os mapas de potencial eletrostático de 6 (Figura 3). Já para as demais conformações (2B, C, E e F) as variações de energia e momento dipolo são menos pronunciadas. Através dos valores de volumes moleculares observados, discrimina-se melhor, outra vez, a conformação antiperiplanar (2A) como 182,38 $\AA^{3}$ da sinperiplanar (2D) que apresenta $176,49 \AA^{3}$. Contudo, para as demais conformações são pequenas as diferenças entre os volumes moleculares encontrados. Adicionalmente, tendo como base a medida das distâncias entre os átomos de nitrogênio e do hidrogênio da metahidroxila catecólica, pode-se observar que nenhuma das conformações (2A-F) apresenta a distância necessária (2,6-3,0 Å) à formação de ligação de hidrogênio. Por outro lado, mais uma vez fica evidente que as distâncias entre os grupamentos farmacofóricos é bastante influenciada por variações conformacionais de $\mathbf{6}$.

De modo geral, pode-se concluir com os dados discutidos acima que tais descritores físico-químicos discriminam satisfatoriamente a conformação antiperiplanar (2A) da sinperiplanar (2D). Para as conformações anticlinais (3A-B) e sinclinais (3D-E) as diferenças são mais sutis, porém não menos importantes, corroborando com a idéia de que diferentes confôrmeros de $\mathbf{6}$ são responsáveis por diferentes formas de reconhecimento molecular pelos cinco sub-tipos de receptores dopaminérgicos.

\section{Variações estruturais e farmacológicas dos receptores dopaminérgicos $D_{1}-D_{5}$ clonados}

O primeiro sub-tipo de receptor dopaminérgico clonado foi o $\mathrm{D}_{2}$ (Figura 5), por homologia ao receptor $\beta_{2}$-adrenérgico, sendo ambos acoplados à proteína $\mathrm{G}^{39}$. Posteriormente, em 1990, quatro grupos de pesquisa, trabalhando independentemente, reportaram a clonagem do sub-tipo de receptor $\mathrm{D}_{1}^{27-30}$. Ainda não há disponibilidade de modelos cristalográficos dos receptores dopaminérgicos já clonados, mas a literatura descreve modelos topográficos para as duas subfamílias $\left(D_{1} \text { e } D_{2}\right)^{39}$. As sub-famílias de receptores dopaminérgicos, $\mathrm{D}_{1}$ e $\mathrm{D}_{2}$, diferem quanto às características funcionais, farmacológicas, estruturais e localização no cérebro (Tabela 2), sendo estes dois receptores expressos em maior número dentre os cinco tipos conhecidos até o momento ${ }^{39,40}$. Estudos posteriores permitiram a clonagem de mais dois sub-tipos de receptores da sub-família $\mathrm{D}_{2}, \mathrm{D}_{3}{ }^{32}$ e $\mathrm{D}_{4}^{33} \mathrm{e}$ um sub-tipo da sub-família $\mathrm{D}_{1}, \mathrm{o}_{5}{ }^{34}$.

A sub-família de receptores $\mathrm{D}_{2}$ apresenta $52 \%$ de homologia com o sub-tipo $\mathrm{D}_{3}$. Quando se consideram apenas os aminoácidos da região transmembrânica (RTM), esta homologia aumenta para 75\%. Entre os sub-tipos $\mathrm{D}_{2}$ e $\mathrm{D}_{4}$, a homologia global é de $41 \%$, aumentando para $56 \%$ na RTM, enquanto que entre os sub-tipos $\mathrm{D}_{3}$ e $\mathrm{D}_{4}$, a homologia

Tabela 1. Cálculos semiempíricos [Spartan 1.0.5 (Wavefunction Inc. Irvine, CA, 2000)], sobre as principais conformações adotadas pela dopamina $(\mathbf{6})^{37}$

\begin{tabular}{ccccc}
\hline Conformações & Energia $(\mathrm{Kcal} \backslash \mathrm{mol})$ & Momento dipolar $(\mu)$ & Distância interatômica $(N$-meta OH) & Volume Molecular $\left(\AA^{3}\right)$ \\
\hline Antiperiplanar (2A) & 0,000 & 5,14 & 6,372 & 182,38 \\
+ Anticlinal (2F) & 1,725 & 3,54 & 5,817 & 181,25 \\
+ Sinclinal (2E) & 1,417 & 4,42 & 4,508 & 180,54 \\
Sinperiplanar (2D) & 5,262 & 7,08 & 3,680 & 176,49 \\
- Sinclinal (2C) & 1,444 & 5,37 & 4,508 & 180,54 \\
- Anticlinal (2B) & 1,727 & 4,90 & 5,817 & 181,25 \\
\hline
\end{tabular}




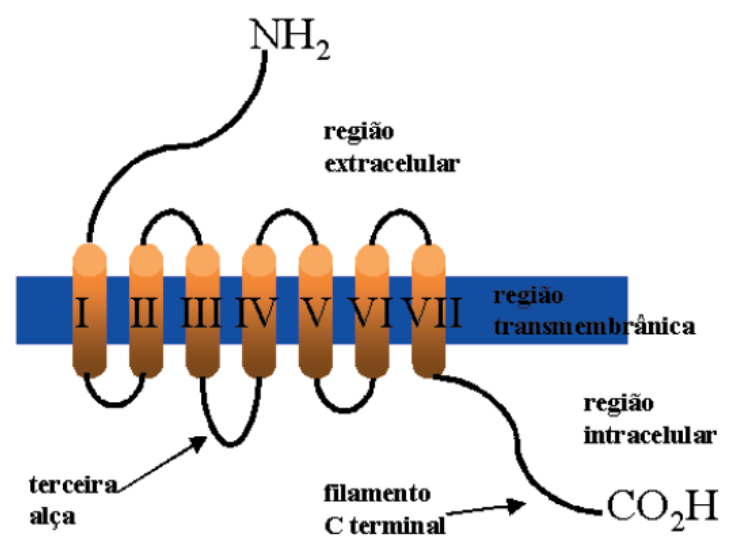

Figura 5. Modelo estrutural dos receptores dopaminérgicos $D_{1}-D_{5}$

global é de $39 \%$ e $56 \%$ na RTM. Na sub-família de receptores $\mathrm{D}_{1}$ a homologia global é de $50 \%$, chegando a $80 \%$ na RTM $^{39,40}$.

As sub-famílias também diferem quanto aos mensageiros intracelulares envolvidos no processo de transdução do sinal, visto que a sub-família $\mathrm{D}_{2}$ inibe a produção de AMPc e a abertura de canais de cálcio, além de estimular a abertura de canais de potássio. Por outro lado, os receptores da sub-família $\mathrm{D}_{1}$ estimulam a produção de AMPc (Tabela 2). Ainda não foi completamente esclarecido como os receptores do sub-tipo $\mathrm{D}_{3}$ interferem com a biossíntese do segundo mensageiro $\mathrm{AMPc}^{39,40}$.

Entre os diversos sub-tipos de receptores dopaminérgicos, observa-se conservação de certos resíduos de aminoácidos, e.g. cisteína C-terminal e aspartato-80 na segunda região transmembrânica, os quais parecem estar conservados em quase todos os receptores acoplados à proteína-G. Estudos de mutagênese ${ }^{41}$ permitiram observar que este resíduo de aspartato-80 é fundamental para a interação e afinidade de derivados benzamídicos e.g. $\mathbf{3}^{23}$, antagonistas seletivos do sub-tipo $\mathrm{D}_{2}$. Em outro estudo, onde se efetuou o ancoramento da dopamina (6) a um modelo de receptor $\mathrm{D}_{2}$ de rodopsina, foi observado que o átomo de nitrogênio catiônico de $\mathbf{6}$ atua como contra-íon do resíduo de aspartato-114, localizado na terceira região transmembrânica, a uma distância de 3,04 $\AA^{42}$.

Adicionalmente, foi observado que a meta-hidroxila catecólica faz ligação de hidrogênio com a serina-194 a uma distância de 2,55 $\AA$ A. Ocorre ainda uma terceira interação do tipo " $\pi$-stacking" do anel aromático de 6 com o resíduo de triptofano-160, distante $8,52 \AA^{42}$ (Figura 6).

Estudos de polimorfismo em receptores $\mathrm{D}_{4}$ demonstraram que a substituição da valina-194, localizada entre os dois resíduos de serina na quinta RTM, por glicina-194, faz os neurolépticos atípicos, como clozapina $(\mathbf{5})^{25}$ e olanzapina (8), perderem a afinidade pelo receptor $^{43}$. Estes mesmos estudos permitiram também observar uma redu-

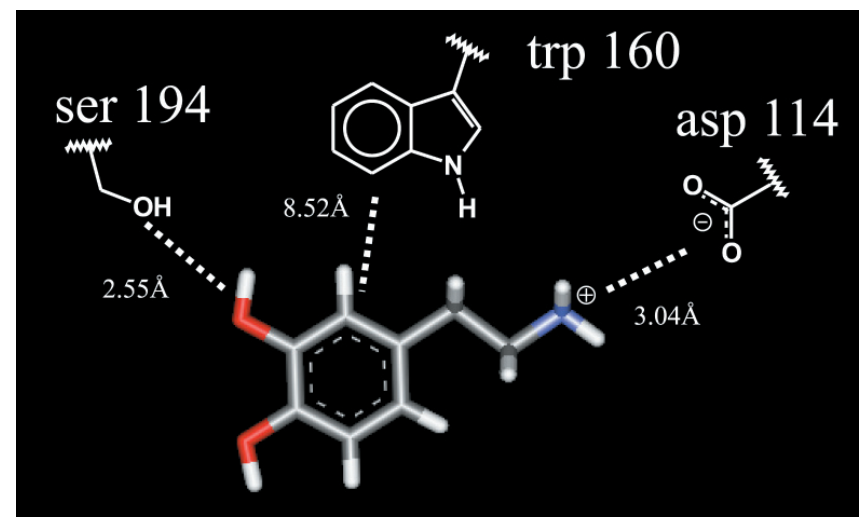

Figura 6. Interações prováveis da dopamina (6) e resíduos de aminoácidos específicos do receptor $D_{2}$. Adaptado da ref. 42

ção em $c a .20 \%$ da afinidade do haloperidol (2) pelo receptor sem, entretanto, refletir em qualquer mudança significativa de afinidade da clorpromazina (1) e da espiperona $(\mathbf{9})^{44}$. Estes resultados sugerem que, possivelmente, a estrutura da quinta RTM deva se encontrar alterada, embora a estrutura global do receptor esteja pouco modificada. Estas conclusões foram possíveis porque as afinidades da dopamina (6), haloperidol (2), clorpromazina (1) e espiperona (9) foram muito pouco afetadas pela mutação do resíduo de aminoácidos em posição $194^{45}$

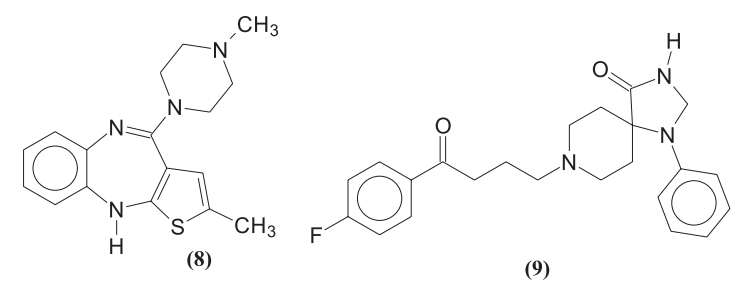

\section{HIPÓTESE DOPAMINÉRGICA DA ESQUIZOFRENIA}

A hipótese dopaminérgica da esquizofrenia começou a ganhar força na década de 60 . Vale mencionar que até meados da década de 50, a dopamina (6), substância essencial para o controle do tônus muscular, postura e coordenação motora, não era considerada como neurotransmissor, mas sim, como intermediário de biossíntese, a partir da L-tirosina (10), das demais aminas biogênicas, nor-adrenalina (12) e adrenalina (13) (Figura 7) ${ }^{46}$.

A primeira evidência da hipótese dopaminérgica em quadros de esquizofrenia foi descrita por Carlsson ${ }^{7,47}$ (Nobel em Medicina, $2001)^{48}$ e Lindqvist, em 1963, quando observaram o acúmulo de metabólitos da dopamina (6), i.e. ácido diidroxifenilacético (14) e ácido homovanílico (16) (Figura 7), no cérebro de coelhos tratados com clorpromazina $(\mathbf{1})^{49}$ e haloperidol $(\mathbf{2})^{22}$. Assumindo que os

Tabela 2. Propriedades dos receptores dopaminérgicos ${ }^{39,40}$

\begin{tabular}{|c|c|c|c|c|c|}
\hline Sub-tipo de Receptor & $\mathrm{D}_{1}$ & $\mathrm{D}_{5}$ & $\mathrm{D}_{2}$ & $\mathrm{D}_{3}$ & $\mathrm{D}_{4}$ \\
\hline a.a Ratos ${ }^{\mathrm{a}}$ & 446 & 477 & $414-443$ & 400 & 387 \\
\hline a.a Humanos & 446 & 475 & $415-444$ & 446 & - \\
\hline Cromossomo Humano & 5 & 4 & 11 & 3 & 11 \\
\hline \multirow[t]{3}{*}{ Via efetoras } & $\uparrow c A M P^{b}$ & $\uparrow \mathrm{cAMP}{ }^{\mathrm{b}}$ & $\downarrow_{\mathrm{cAMP}} \mathrm{c}$ & $\downarrow_{c A M P} ?$ & $\downarrow_{c A M P} ?$ \\
\hline & - & - & $\uparrow$ canal K+ & - & c \\
\hline & - & - & $\downarrow_{\text {canal }} \mathrm{Ca}+$ & - & - \\
\hline
\end{tabular}

${ }^{\mathrm{a} A m i n o-a ́ c i d o s ; ~}{ }^{\mathrm{b}}$ Estimula a produção de cAMP; ${ }^{\mathrm{c}}$ Inibe a produção de cAMP. 
antipsicóticos 1 e 2 bloqueiam os receptores $D_{2}$ pós-sinápticos, os autores propuseram que poderia estar ocorrendo recaptação neuronal do excesso de 6, com subseqüente bioformação de 14 e 16 por ação das enzimas catecol- $O$-metiltransferase (COMT) e monoamino oxidase $(\mathrm{MAO})^{7}$.

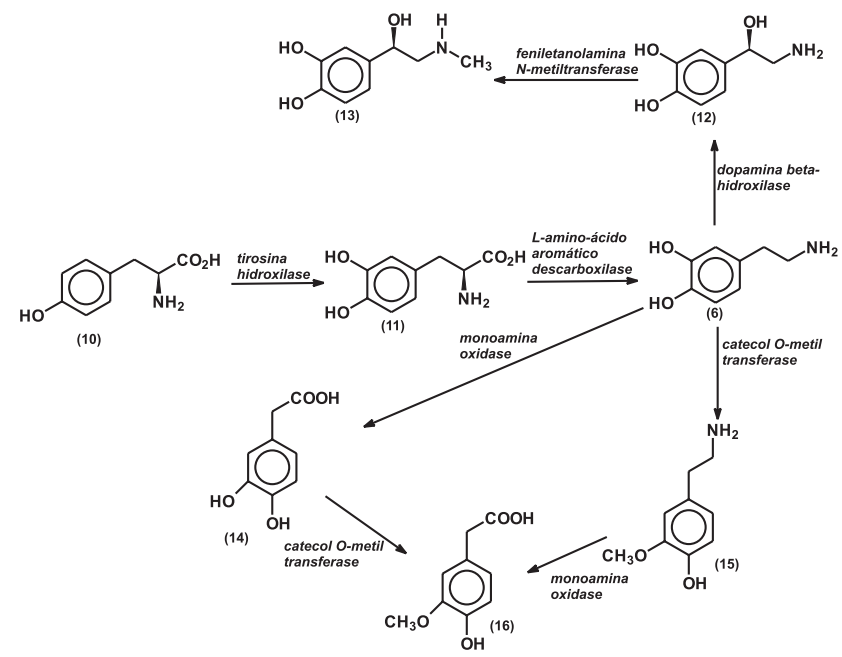

Figura 7. Via biossintética e metabólica da dopamina (6). Adaptada da ref. 46

Posteriormente, Horn e Snyder ${ }^{50}$ observaram que havia uma similaridade conformacional entre a estrutura cristalográfica da clorpromazina (1), primeiro antipsicótico efetivo no tratamento dos sintomas positivos da esquizofrenia e aquela da dopamina (6) (Figura 8$)^{20,50}$. Com base nestas evidências, foi racionalizado pela primeira vez que o perfil terapêutico da clorpromazina (1) estava relacionado com a modulação de receptores dopaminérgicos.

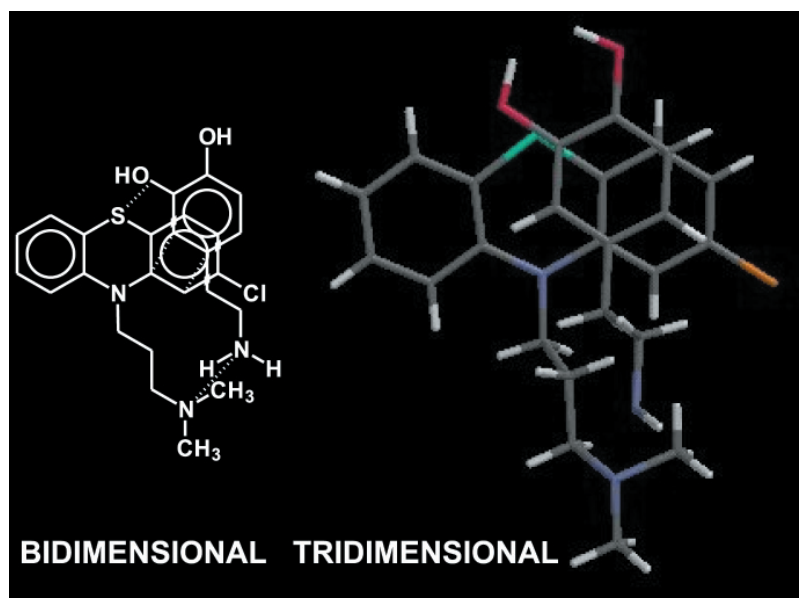

Figura 8. Sobreposições bidimensional e tridimensional das estruturas cristalográficas da clorpromazina (1) e da dopamina (6). Adaptada da ref. 50

Outra evidência que associa a via dopaminérgica com a fisiopatologia da esquizofrenia foi obtida através de estudos in vitro, empregando homogenato do cérebro de ratos. Nestes estudos, foram correlacionadas as doses clínicas médias de vários antipsicóticos, com suas concentrações inibitórias $50 \%\left(\mathrm{IC}_{50}\right)$ relativas ao deslocamento dos radioligantes $\left[{ }^{3} \mathrm{H}\right]$ haloperidol e $\left[{ }^{3} \mathrm{H}\right]$ dopamina, previamente incorporados ao tecido ${ }^{51,52}$. Os dados obtidos deste trabalho constituíram a primeira evidência direta de que os antipsicóticos compe- tem com a dopamina (6) por seus sítios específicos de reconhecimento molecular ${ }^{51,52}$.

No mesmo contexto, Snyder observou que fármacos simpatomiméticos de ação indireta, e.g. anfetamina $(\mathbf{1 7})^{53,54}$, que promovem a liberação de dopamina $(\mathbf{6})^{55,56}$, levam ao desenvolvimento de um quadro de paranóia semelhante àquele manifestado por pacientes esquizofrênicos, o qual pode ser inibido pela administração de antagonistas dos receptores $\mathrm{D}_{2}$.

Seeman e colaboradores também demonstraram que ocorre aumento da população de receptores dopaminérgicos no cérebro de pacientes esquizofrênicos. Este aumento foi mais pronunciado para os receptores do sub-tipo $\mathrm{D}_{4}(60 \%)$, enquanto que o aumento das populações dos sub-tipos $\mathrm{D}_{2}$ e $\mathrm{D}_{3}$ foi menos pronunciado (10\%), constituindo assim, evidência adicional da hiperatividade dopaminérgica na esquizofrenia ${ }^{57}$.

Embora a hipótese dopaminérgica ainda seja polêmica ${ }^{56,58-60}$, outros estudos recentes sugerem fortemente que pacientes esquizofrênicos apresentam hiperatividade dopaminérgica ${ }^{61}$. Abi-Dargham e colaboradores elaboraram um experimento onde a biossíntese de dopamina (6) foi inibida farmacologicamente. Então, procedeu-se à medida da diferença da população de receptores $\mathrm{D}_{2}$ em indivíduos sadios e esquizofrênicos, antes e após a depleção de 6, i.e. $9 \% \pm 7 \%$ e $19 \% \pm 11 \%$, respectivamente. A leitura do número de receptores foi obtida por tomografia de emissão de fóton simples (SPECT), que avalia os receptores previamente ligados com $(S)-(-)-3-\left[{ }^{123} I\right]$ iodo-2hidroxi-6-metoxi- $N$-[(1-etil-2-pirrolinil)metil] benzamida (18). Estes resultados possibilitaram concluir que, em pacientes esquizofrênicos, ocorre tanto uma hiperprodução de dopamina (6) no neurônio pré-sináptico, como o aumento da densidade de receptores do sub-tipo $\mathrm{D}_{2}$ na membrana pós-sináptica ${ }^{61}$.

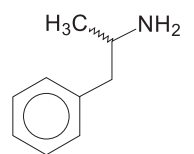

(17)

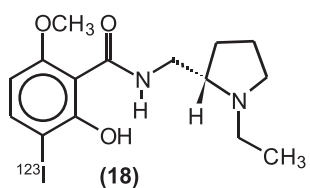

(18)
A segunda hipótese mais aceita para a gênese da esquizofrenia é a serotoninérgica, evidenciada através da observação de que agonistas de receptores de serotonina (19), e.g. mescalina (20) e a dietilamida do ácido lisérgico (LSD) (21), produzem alucinações semelhantes àquelas observadas em pacientes esquizofrênicos ${ }^{1}$. Muito embora alguns fármacos como a clozapina (5) apresentem afinidade pelos receptores serotoninérgicos do sub-tipo 5- $\mathrm{HT}_{2}$, os dados disponíveis não permitem concluir com precisão sobre a relevância deste tipo de abordagem terapêutica para o tratamento da esquizofrenia ${ }^{1}$.<smiles>[2H]n1cc2c3c(cccc31)C1=C[C@@H](C(=O)N(CC)CC)CN(C)[C@@]1(C)C2</smiles>

\section{HISTÓRICO DA EVOLUÇÃO DOS FÁRMACOS ANTIPSICÓTICOS CLÁSSICOS}

\section{Derivados fenotiazínicos}

A descoberta do destacado potencial terapêutico dos fármacos 
fenotiazínicos, representados pela clorpromazina (1), deu-se por acaso, quando se observou que a introdução da sub-unidade heterocíclica fenotiazina em fármacos anti-histamínicos causava sedação excessi$\mathrm{va}^{20,49}$.

Os benzodioxanos, e.g. 22, derivados éteres de etanolaminas, estão entre os primeiros fármacos a serem empregados como antihistamínicos ${ }^{46}$. Sobre a estrutura química de $\mathbf{2 2}$ foram introduzidas várias simplificações moleculares que conduziram a novos éteres de etanolaminas acíclicas, e.g. 23, os quais por sua vez deram origem aos derivados etilenodiaminas, e.g. 24, através da substituição isostérica do átomo de oxigênio pelo de nitrogênio. Posteriormente, novas modificações moleculares incorporaram os derivados etilenodiaminas, entre eles $\mathbf{2 4}$, ao átomo de nitrogênio do núcleo fenotiazínico, dando origem à dietazina (25). Estes novos derivados, além de apresentarem atividade anti-histamínica, também demonstraram um forte efeito sedante, tornando seu uso mais adequado no tratamento da doença de Parkinson. O isóstero prometazina (26) mostrou-se terapeuticamente útil como anti-histamínico ${ }^{46}$ (Figura 9).<smiles>C=CC</smiles><smiles>C=C=C</smiles><smiles>CCN(CCN(C)C)c1ccccc1</smiles>
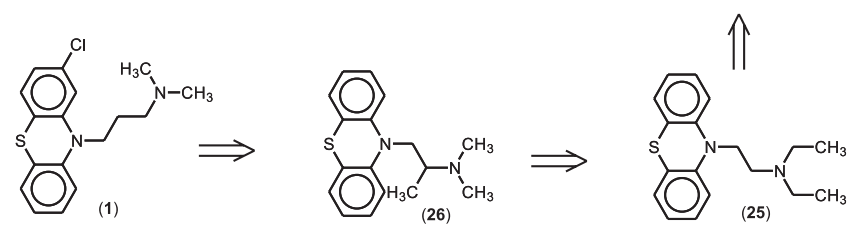

Figura 9. Gênese dos antipsicóticos fenotiazínicos 1. Adaptada da ref. 46

Além de seu perfil anti-histamínico, a prometazina (26) também possui habilidade de prolongar o sono induzido por barbitúricos, sendo seu emprego terapeuticamente útil na anestesia clínica. A avaliação das propriedades farmacológicas de vários análogos de $\mathbf{2 6}$ conduziu Charpentier à síntese da clorpromazina (1), em 1950. Logo de início, foi observado que a clorpromazina (1) gerava uma predisposição ao sono e desinteresse geral, sem que houvesse perda de consciência. Após sua introdução como antipsicótico na França, em 1951, foi observado que, além do seu efeito sobre a agitação e ansiedade, esta substância também era efetiva no tratamento de psicoses ${ }^{46}$.

\section{Derivados butirofenônicos}

As butirofenonas (2) compõem outra classe de antipsicóticos clássicos usualmente empregados na terapêutica, que tiveram seu perfil farmacológico caracterizado por acaso ${ }^{46}$.

A descoberta das butirofenonas decorreu da tentativa de otimizar a atividade analgésica da meperidina (27), quando foram sintetizados análogos nor-meperidínicos. Desta forma foram obtidos os análogos propiofenônicos (28), que apresentam potência analgésica cerca de 200 vezes superior à de $\mathbf{2 7}$, enquanto os homólogos butirofenônicos (29) demonstraram um perfil semelhante ao observado para a clorpromazina (1) (Figura 10).

Após a descoberta do protótipo haloperidol (2), novas modificações foram introduzidas sobre seu padrão estrutural, que resultaram na obtenção de novos análogos, tais como espiperona (9) e droperidol (29), que variam quanto à potência e propriedades farmacocinéticas. Através de estudos sobre a relação entre a estrutura química e a atividade farmacológica (SAR) desta família de compostos, foi possível estabelecer-se um esqueleto mínimo necessário para a atividade pre- tendida. Estes requisitos estruturais mínimos compreendem o átomo de nitrogênio terciário, ligado a uma cadeia alquílica de quatro átomos de carbono pertencente ao esqueleto butirofenônico (a), substituído na posição para do anel aromático por um átomo de flúor. $\mathrm{O}$ átomo de nitrogênio terciário, geralmente, está inserido em um anel alifático de seis membros, na maioria das vezes substituídos na posição $4^{46}$ (Figura 10).

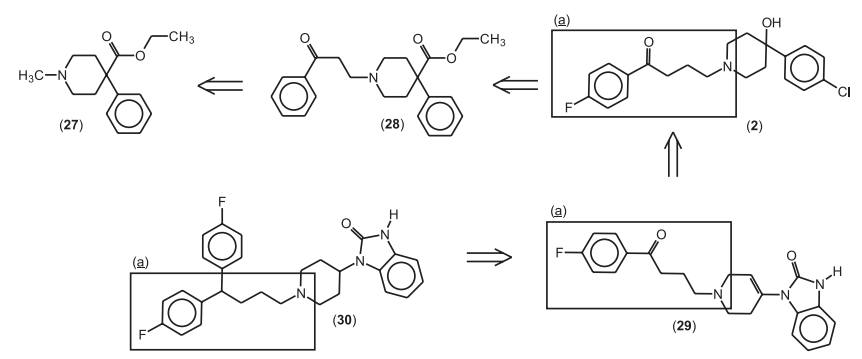

Figura 10. Gênese dos antipsicóticos butirofenônicos 2. Adaptada da ref. 46

A introdução de uma segunda sub-unidade 4-fluorfenila no esqueleto básico das butirofenonas 29 deu origem aos análogos difenilbutilpiperidínicos, tais como o pimozido (30) que, ao contrário das butirofenonas, apresentam maior tempo de meia vida plamática $^{46}$ (Figura 10).

\section{Novos derivados análogos à clozapina (5), sintetizados no LASSBio}

Devido ao fato de a clozapina (5) ter demonstrado um perfil terapêutico diferenciado dos antipsicóticos clássicos, seu núcleo [8cloro-11-(4-metil-1-piperazinil)-5H-dibenzo [1,4] diazepina] foi extensamente estudado, visando-se obter compostos que apresentassem semelhante perfil terapêutico sem, contudo, apresentar seus efeitos colaterais ${ }^{62-64}$.

O emprego de estratégias racionais de modificação molecular sobre a estrutura da clozapina (5), incluindo trocas isotéricas, simplificações estruturais, contrações de anel, não lograram na obtenção de análogos com perfis de bioatividade e toxicidade significativamente superiores ao protótipo ${ }^{63-65}$, mas permitiram hierarquizar as sub-unidades moleculares de maior relevância para a atividade central, tornando possível a obtenção de novos derivados heterocíclicos, e.g. $31^{66}$, apresentando seletividade funcional $\left(\mathrm{K}_{\mathrm{i}}=3,6 \mathrm{nM}\left[\mathrm{D}_{4}\right]\right.$, $\mathrm{K}_{\mathrm{i}}=2250 \mathrm{nM}\left[\mathrm{D}_{2}\right]$ e $\left.\mathrm{K}_{\mathrm{i}}>8000 \mathrm{nM}\left[\mathrm{D}_{3}\right]\right)^{68,69}$ (Figura 11).
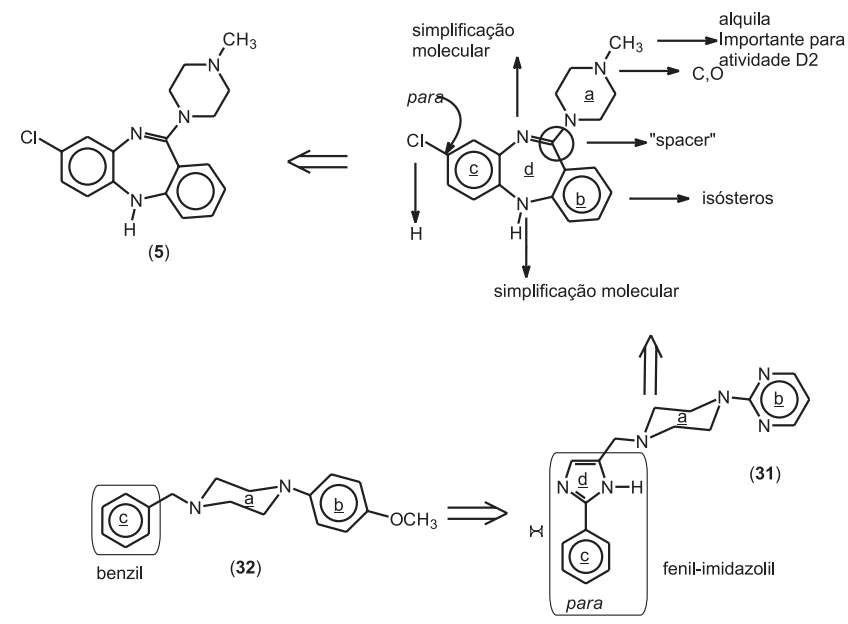

Figura 11. Modificações estruturais da clozapina (5) e gênese dos derivados fenilpiperazínicos 31 e 32 
Simplificações moleculares posteriores na estrutura do derivado 31, através da troca da sub-unidade fenil-imidazolila com $6+6$ elétrons $\pi$ pela sub-unidade benzílica com 6 elétrons $\pi$, lograram na obtenção do novo padrão molecular 32, sem implicar em perda da seletividade funcional $\left(\mathrm{K}_{\mathrm{i}}=93 \mathrm{nM}\left[\mathrm{D}_{4}\right], \mathrm{K}_{\mathrm{i}}>2250 \mathrm{nM}\left[\mathrm{D}_{2} \mathrm{e} \mathrm{D}_{3}\right]\right)^{68}$ (Figura 11).

Como ilustrado na Figura 12, após se identificar a possibilidade de prototropia no derivado $\mathbf{3 1}$, duas novas famílias de derivados heterocíclicos, isostéricas entre si, foram planejadas explorando a variação do padrão de substituição da sub-unidade $N$-arilazola, i.e. $N$-fenilpirazola (33) e $N$-fenil-1,2,3-triazola em (34), de forma a evitar a prototropia e tentar otimizar eventualmente o seu perfil como ligantes de receptores dopaminérgicos. Os novos candidatos 33 e 34 apresentam, adicionalmente, diferenças de substituição nas posições 3 e 5 do anel heterocíclico, vizinhas à unidade metilênica (Figura 12). Desta forma, observa-se que no núcleo pirazólico 33 há simetria entre ambas as posições orto (3 e 5) e a cadeia metilênica. Por outro lado, a mesma simetria não é observada para os derivados 34 apresentando o núcleo 1,2,3-triazólico, visto que nas posições orto correspondentes, há um átomo de nitrogênio na posição 3 e um átomo de carbono na posição 5. Provavelmente, pode-se concluir que tais nuances estruturais talvez possam conferir efeitos conformacionais distintos para as duas famílias $\mathbf{3 3}$ e $\mathbf{3 4}$ podendo, eventualmente, refletir em seu perfil farmacológico ${ }^{69-71}$.
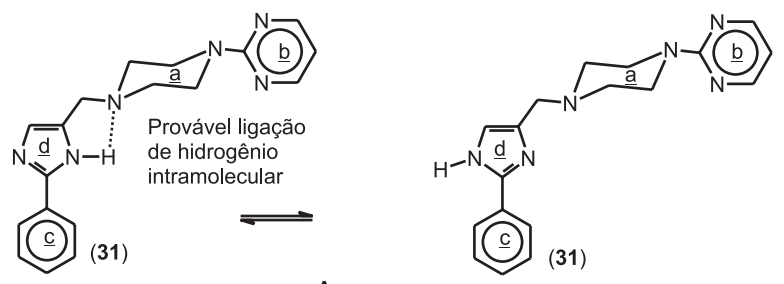

$\Uparrow$

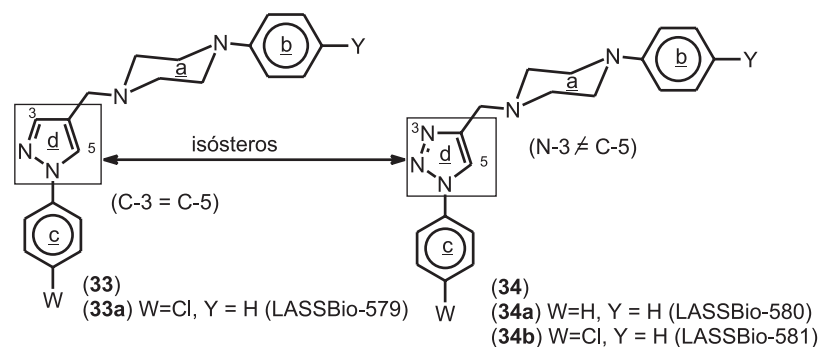

Figura 12. Novos derivados pirazólicos 33 e 1,2,3-triazólicos 34 estruturalmente planejados a partir do protótipo imidazólico 31

O padrão de substituição da sub-unidade fenila foi eleito a fim de se analisar os efeitos eletrônicos $(\sigma)$, hidrofóbicos $(\pi)$, bem como efeitos estéricos (RM) dos substituintes ${ }^{72}$ (Tabela 3). Ademais, estudos de modelagem molecular para se avaliar aspectos conformacionais e estereoeletrônicos destas duas novas famílias de compostos foram objeto da dissertação de mestrado de Macchi $\mathrm{Jr}^{37}$.

Os novos derivados 33-34 foram submetidos a ensaios eletrofisiológicos in vitro, realizados pelos Dr. E. F. R. Pereira e E. $X$. Albuquerque (Dept. of Pharmacology and Experimental Therapeutic, School of Medicine, University of Maryland, EUA) e os resultados indicaram o destacado e seletivo perfil ligante de receptores dopaminérgicos $\mathrm{D}_{2}$ para os derivados LASSBio-579 (33a), LASSBio-580 (34a) e LASSBio-581 (34b). Adicionalmente, foi possível distinguir a atividade intrínseca destas substâncias e correlacioná-la com o padrão de substituição $\underline{\mathrm{W}}$, uma vez que os
Tabela 3. Descritores físico-químicos dos substituintes dos anéis fenila de $\mathbf{3 3 - 3 4}{ }^{72}$

\begin{tabular}{lccc}
\hline Substituinte $(\mathrm{W})$ & $\sigma_{\mathrm{p}}$ & $\pi_{\mathrm{p}}$ & $\mathrm{RM}$ \\
\hline $\mathbf{H}$ & 0,00 & 0,00 & 1,03 \\
$\mathbf{F}$ & 0,06 & 0,15 & 0,92 \\
$\mathbf{C l}$ & 0,23 & 0,73 & 6,03 \\
$\mathbf{N O}_{2}$ & 0,78 & 0,22 & 7,36 \\
$\mathbf{O C H}_{3}$ & $-0,27$ & $-0,03$ & 7,87 \\
$\mathbf{N H}_{2}$ & $-0,66$ & $-1,30$ & 5,42 \\
$\mathbf{N H C O C H}_{3}$ & 0,00 & $-0,56$ & 14,93 \\
\hline
\end{tabular}

derivados para-clorados 33a e 34b mostraram ser agonistas de receptores $\mathrm{D}_{2}$, enquanto que o derivado não substituído 34a é antagonista $\mathrm{D}_{2}^{73}$. De posse destes resultados, o derivado LASSBio-581 (34b) foi submetido à avaliação farmacológica em modelos comportamentais realizados no grupo da Dra S. M. K. Rates (Faculdade de Farmácia, Universidade Federal do Rio Grande do Sul). Com base nos resultados obtidos nos experimentos de catalepsia e estereotipia induzida por anfetamina é possível concluir que 34b apresenta um efeito inibitório sobre o sistema dopaminérgico, o qual somado à sua baixa toxicidade aguda ${ }^{74}\left(\mathrm{DL}_{50}=707 \mathrm{mg} / \mathrm{Kg}\right)$, torna este composto um futuro candidato a protótipo de fármaco antipsicótico.

\section{CONCLUSÕES}

A esquizofrenia, fortuitamente definida como desordem associativa pelo médico suíço Eugen Bleuler em 1908, é uma doença para qual, até os dias de hoje, só existe tratamento paliativo. No entanto, o crescente interesse das grandes companhias farmacêuticas e da academia têm contribuído, ainda que singelamente, para uma melhor compreensão da fisiopatologia da doença.

Ademais, o constante aperfeiçoamento e aumento do volume de trabalhos interdisciplinares, envolvendo áreas complementares como o genoma humano, técnicas de clonagem de receptores, métodos analíticos não-invasivos mais sensíveis que os disponíveis até o momento, além de novas ferramentas farmacológicas decorrentes do desenvolvimento de ligantes seletivos para os sub-tipos de receptores dopaminérgicos, fazem emergir novas perspectivas.

Pelo exposto, torna-se evidente a mudança de paradigma na busca de novos candidatos a protótipos de agentes antipsicóticos, uma vez que estes agora passam a ser planejados racionalmente, ao invés de serem descobertos como foram a clorpromazina (1) e o haloperidol (2).

\section{AGRADECIMENTOS}

Os autores agradecem ao PROCAD-CAPES, CNPq, FAPERJ e FUJB, pelo apoio financeiro e bolsas concedidas. Adicionalmente, os autores agradecem ao aluno de pós-graduação I. L. Macchi Jr. (Faculdade de Farmácia, UFRGS) pelos dados referentes a Figura 3 e Tabela 1.

\section{GLOSSÁRIO}

Acatisia: (G. $a$-, privação de + kathisis, assento) neurose caracterizada por uma incapacidade de permanecer em posição sentada; inquietação motora e sensação de tremor muscular ${ }^{75}$.

Agranulocitose: condição aguda caracterizada por pronunciada leucopenia, acompanhada de grande redução no número de leucócitos polimorfonucleares ${ }^{75}$.

Alelos: são duas ou mais formas alternativas de um gene em locus particular, que confere características alternativas ${ }^{76}$. 
Antipsicóticos atípicos: fármacos empregados na terapêutica da esquizofrenia, que apresentam baixos níveis de efeitos extrapiramidais e sintomas Parkinsonianos ${ }^{75}$.

Antipsicóticos clássicos: fármacos empregados na terapia da esquizofrenia, que apresentam como principais efeitos colaterais os sintomas extrapiramidais e Parkinsonianos ${ }^{75}$.

Bradicinesia: (bradys, lento + kinesis, movimento) extrema lentidão de movimento.

Constante de inibição $\left(K_{i}\right)$ : é dado físico-químico, expresso através de valor numérico que traduz a afinidade de uma micromolécula por uma biomacromolécula, seja ela enzima ou receptor. Estes dados são obtidos por meio da fórmula: $\mathrm{K}_{\mathrm{i}}=\mathrm{IC}_{50} /\left(1+[\mathrm{L}] / \mathrm{K}_{\mathrm{d}}\right)$, onde $\mathrm{IC}_{50}$ é a concentração inibitória de $50 \%$ do deslocamento do radioligante; $\mathrm{L}$ a concentração do radioligante; e $\mathrm{K}_{\mathrm{d}}$ a constante de dissociação do complexo micromolécula-biomacromolécula ${ }^{17}$.

Discinesia tardia: dificuldade em realizar movimentos voluntá$\operatorname{rios}^{75}$.

Distonia: distúrbio da tensão, da tonicidade ou tônus; modificação patológica das ações musculares que mantêm o homem em equilíbrio na posição em pé p̧$^{\text {. }}$.

Efeitos extrapiramidais (catalepsia): (G. katalepsis, convulsão, kata, para baixo + lepsis, convulsão) estado mórbido, aliado à autohipnose ou à histeria, em que há rigidez dos membros, os quais podem ser colocados em várias posições, nelas se mantendo durante certo tempo. O indivíduo não responde aos estímulos; o pulso e a respiração são lentos e a pele é pálida ${ }^{75}$.

Esquizofrenia: (G. schizõ- dividir ou clivar + G. phren- mente) termo cunhado por Bleuler, que veio substituir a denominação demência precoce; o tipo mais comum de psicose, caracterizado por um distúrbio nos processos de raciocínio, tais como ilusões e alucinações e extenso retraimento do interesse do indivíduo em relação a outras pessoas e ao mundo exterior, assim como à introversão em si mesmo. A esquizofrenia hoje é considerada uma síndrome, que pode ser classificada em ambulatorial, catatônica, latente, heberfrênica, paranóide, processual, pseudoneurótica, reativa e simples ${ }^{75}$.

Hiperprolactinemia: produção exacerbada de prolactina, um hormônio protéico da pituitária anterior que estimula a secreção de leite e crescimento das mamas durante o período de lactação. A secreção exacerbada de prolactina deve-se ao bloqueio excessivo de receptores dopaminérgicos do sub-tipo $\mathrm{D}_{2}$ no lobo anaterior da hipófise $^{75}$.

Leucócitos polimorfonucleares: (leuko- + G. kutos, célula) são as células brancas do sangue, abrangendo os basófilos, eosinófilos e neutrófilos, principalmente este último ${ }^{75}$.

Lobotomia: técnica cirúrgica desenvolvida pelo médico português Égaz Moniz, que lhe valeu o Prêmio Nobel de Medicina em 1950, e consiste em extirpar parte do lobo frontal do cérebro de pacientes que apresentavam comportamento emocional violento ${ }^{21}$.

Paranóia: (G. perturbação, loucura, de para- + nõeo-, pensar) distúrbio mental grave porém raro, caracterizado pela presença de delírios sistematizados, muitas vezes de caráter persecutório, em uma personalidade intacta sob outros aspectos. Quando os sintomas são relativamente brandos e a enfermidade mental não existe, a condição é chamada de personalidade paranóica ${ }^{75}$.

Polimorfismo: é a existência de duas ou mais formas alternativas ou variantes de um gene particular que estão presentes em frequiência estável em uma população. Cada variante comum de um gene polimórfico é chamada de alelo e um indivíduo pode carregar dois diferentes alelos de um gene, um herdado do pai e outro da mãe ${ }^{77}$.

Sintomas Parkinsonianos: sintomas que mimetizam o comportamento de pacientes acometidos pela doença de Parkinson, associado à hipoatividade dopaminérgica na via nigro-striatal. Os antipsicóticos clássicos bloqueiam os receptores dopaminérgicos do sub-tipo $\mathrm{D}_{2}$ pós-sinápticos, o que limita o acesso do agonista endógeno dopamina (6) ao seu receptor, onde desencadeia uma cascata de eventos intracelulares ${ }^{75}$.

\section{REFERÊNCIAS}

1. Rowley, M.; Bristow, L. J.; Huston, P. H.; J. Med. Chem. 2001, 44, 477; Wong, A. H. C.; Van Tol, H. H. M.; Neurosci. Biobehav. Rev. 2003, 27, 269

2. Brzustowicz, L. M.; Hodgkinson, K. A.; Chow, E. W. C.; Honer, W. G.; Bassett, A. S.; Science 2000, 288, 678.

3. Owens, J.; Drug Disc. Today 2001, 6, 443.

4. Bleuler, M.; Am. J. Psychiatry 1973, 130, 991.

5. Bleuler, M.; Bleuler, R.; Brit. J. Psychiatry 1986, 149, 661

6. Carlsson, A.; Waters, N.; Waters, S.; Carlsson, M. L.; Brain Res. Inter. 2000 , 31,342 .

7. Carlsson, A.; Lindqvist, M.; Acta Pharmacol. Toxicol. 1963, 20, 140.

8. Busatto, G. F.; Kerwin, R. W.; J. Psychopharmacol. 1997, 11, 3.

9. Tamminga, C. A.; Crit. Rev. Neurobiol. 1998, 12, 21.

10. Hong, F.; Cusack, B.; Fauq, A.; Richelson, E.; Curr. Med. Chem. 1997, 4, 421 .

11. Shlik, J.; Vasar, E.; Bradwejn, J.; CNS Drugs 1997, 8, 134.

12. Bodick, N. C.; Offen, W. W.; Levey, A. I.; Cutler, N. R.; Gauthier, S. G.; Satin, A.; Shannon, H. E.; Tollefson, G. D.; Rasmussen, K.; Bymaster, F. P.; Hurley, D. J.; Potter, W. Z.; Paul, S. M.; Arch. Neurol. 1997, 54, 465.

13. Ferre, S.; Psychopharmacol. 1997, 133, 107.

14. Abou-Gharbia, M.; Ablordeppey, S. Y.; Glennon, R. A.; Annu. Rep. Med. Chem. 1993, 28, 1.

15. Gattaz, W. F.; Schmitt, A.; Maras, A.; Schizophr. Res. 1995, 16, 1; Tavares Jr, H.; Yacubian, J.; Talib, L. L.; Barbosa, N. R.; Gattaz, W. F.; Schizophr. Res. 2003, 61, 1.

16. Wilson, J. M.; Sanyal, S.; Van Tol, H. H. M.; Eur. J. Pharmacol. 1998 , 351, 273; Yang, Y. K.; Chiu, N. T.; Chen, C. C.; Chen, M.; Yeh, T. L.; Lee, I. H.; Psychiatry Res. 2003, 123, 191.

17. Cheng, Y.; Prossof, W. H.; Biochem. Pharmacol. 1973, 22, 3099.

18. Andreasen, N. C.; Olsen, S.; Arch. Gen. Psychiatry 1982, 39, 789.

19. Gilman, S.; Newman, S. W.; Manter and Gat'z Essential of Clinical Neuroanatomy and Neurophysiology, $9^{\text {th }}$ ed., F. A. Davis Company: Filadelphia, 1996.

20. Kyburz, E. Em Third SCI-RSC Medicinal Chemistry Symposium; Lambert, R. W., ed.; Royal Society of Chemistry, 1986, p. 109.

21. Sacks, O.; Um Antropólogo em Marte, $2^{\mathrm{a}}$ ed., Compania das Letras: São Paulo, 1995.

22. Janssen, P. A. J.; van de Westering, C.; Jageneu, A. H. M.; Demoen, P. J. A.; Hermans, B. K. F.; van Daele, G. H. P.; Schellekens, K. H. L.; van der Eycken, C. A. M.; Niemegeers, C. J. E.; Chem. Pharmacol. 1959, 1, 281.

23. Miller, C. S.; Engelhardt, W.; Engelhardt, E. L.; Valley, G.; Thominet, P.; Thominet, M. L.; US pat. 3.342.826 1967.

24. Dunitz, J. D.; Eser, H.; Strickler, P.; Helv. Chim. Acta 1964, 47, 1897.

25. Wander, A.; FR pat. 1.334.944 1963.

26. Fitton, A.; Heel, R. C.; Drugs 1990, 40, 722.

27. Dearry, A.; Gingrich, J. A.; Falardeau, P.; Fremeau Jr, R. T.; Bates, M. D.; Caron, M. G.; Nature 1990, 347, 72.

28. Zhou, Q.; Grandy, D. K.; Thambi, L.; Kushner, J. A.; van Tol, H. H. M.; Cone, R.; Pribnow, D.; Salon, J.; Bunzow, J. R.; Civelli, O.; Nature 1990, $347,76$.

29. Sunahara, R. K.; Niznik, H. B.; Weiner, D. M.; Stormann, T. M.; Brann, M. R.; Kennedy, J. L.; Gelernter, J. E.; Rozmahel, R.; Yang, Y.; Israel, Y.; Seeman, P.; O'Dowd, B. F.; Nature 1990, 347, 80.

30. Monsma, F. J.; Mahan, L. C.; McVittie, L. D.; Gerfen, C. R.; Sibley, D. R.; Proc. Natl. Acad. Sci. U.S.A. 1990, 87, 6723.

31. Bunzow, J. R.; van Tol, H. H. M.; Grandy, D. K.; Albert, P.; Salon, J.; Christie, M. D.; Machida, C. A.; Neve, K. A.; Civelli, O.; Nature 1988, 336, 783

32. Sokoloff, P.; Giros, B.; Martres, M. P.; Bouthenet, M. L.; Schwarts, J. C.; Nature 1990, 347, 146.

33. van Tol, H. H. M.; Bunzow, J. R.; Guan, H. C.; Sunahara, R. K.; Seeman, P.; Niznik, H. B.; Civelli, O.; Nature 1991, 350, 610.

34. Sunahara, R. K.; Guan, H. C.; O’Dowd, B. F.; Seeman, P.; Laurier, L. G.; Ng, G.; George, S. R.; Torchia, J.; van Tol, H. H. M.; Niznik, H. B.; Nature 1991, 350, 614.

35. Potapov, V.; Stereochemistry, $1^{\text {th }}$ ed., MIR Publischers: Moscou, 1979.

36. Barreiro, E. J. L.; Fraga, C. A. M.; Química Medicinal: As Bases Moleculares da Ação dos Fármacos, $1^{\text {a }}$ ed., ArtMed: Porto Alegre, 2001.

37. Macchi Jr., I. L.; Dissertação de Mestrado, Universidade Federal do Rio Grande do Sul, Brasil, 2001. 
38. Aliste, M. P.; J. Mol. Struct.(Theochem) 2000, 507, 1.

39. Sibley, D. R.; Monsma Jr, F. J.; Trends Pharmacol. Sci. 1992, 13, 61.

40. Emilien, G.; Maloteaux, J.; Geurts, M.; Hoogenberg, K.; Cragg, S.; Pharmacol. Ther. 1999, 84, 133.

41. Neve, K. A.; Cox. B. A.; Henningsen, R. A.; Spanoyannis, A.; Neve, R. L.: Mol. Pharmacol. 1991, 39, 733 .

42. Wilcox, R. E.; Tseng, T.; Brusniak, M. K.; Gisburg, B.; Pearlman, R. S.; Teeter, M.; DuRand, C.; Starr, S.; Neve, K. A.; J. Med. Chem. 1998, 41, 4385.

43. Chakrabarti, J. K.; Hotten, T. M.; Tupper, D. E.; US pat. 5.229.382 1993.

44. Janssen, P. A. J.; US pat. 3.155.669 1964.

45. van Tol, H. H. M.; Adv. Pharmacol. 1998, 42, 486.

46. Foye, W. O.; Pricipies of Medicinal Chemistry, $4^{\text {th }}$ ed., Williams \& Wilkins: New York, 1995.

47. Abbott, A.; Nature 2000, 407, 661.

48. Benes, F. M.; Trends Pharmacol. Sci. 2001, 22, 46.

49. Charpentier, P.; Gailliot, P.; Jacob, R.; Gaudechon, J.; Buisson, P.; Acad. Sci. 1952, 235, 59.

50. Horn, A. S.; Snyder, S. H.; Proc. Natl. Acad. Sci. U.S.A. 1971, 68, 2325.

51. Seeman, P.; Chau-Wong, M.; Tedesco, J.; Wong, K.; Proc. Natl. Acad. Sci. U.S.A. 1975, 72, 4376.

52. Seeman, P.; Lee, T.; Chau-Wong, M.; Wong, K.; Nature 1976, 261, 717.

53. Solomon, H.; Snyder, M. D.; Am. J. Psychiatry 1973, 130, 61.

54. Hartung, W. H.; Munch, J. C.; J. Am. Chem. Soc. 1931, 53, 1875.

55. Hardmann, J.; Goodman \& Gilman's The Pharmacological Basis of Therapeutics, $9^{\text {th }}$ ed., MacGraw-Hill: New York, 1996.

56. Laruelle, M.; Abi-Dargham, A.; Van Dyck, C. H.; Gil, R.; D’Souza, C. D.; Erdos, J.; McCance, E.; Rosenblatt, W.; Fingado, C.; Zoghbi, S. S.; Baldwin, R. M.; Seibyl, J. P.; Krystal, J. H.; Charney, D. S.; Innis, R. B.; Proc. Natl. Acad. Sci. U.S.A. 1996, 93, 9235.

57. Seeman, P.; Guan, H. C.; van Tol, H. H. M.; Nature 1993, 365, 441.

58. Lipska, B.; Weinberger, D. R.; Drugs of Today 1997, 33, 103.

59. Seeman, P.; Tallerico, T.; Am. J. Psychiatry 1999, 156, 876.

60. Zawarynski, P.; Tallerico, T.; Seeman, P.; Lee, S. P.; O’Dowd, B. F.; George, S. R.; Fed. Eur. Biochem. Soc. Lett. 1998, 441, 383.

61. Abi-Dargham, A.; Rodenhiser, J.; Printz, D.; Zea-Ponce, Y.; Gil, R.; Kegeles, L. S.; Weiss, R.; Cooper, T. B.; Mann, J. J.; van Heertum, R. L.; Gorman, J. M.; Laurelle, M.; Proc. Natl. Acad. Sci. U.S.A. 2000, 97, 8104; Tsai, S. J.; Hong, C. J.; Schizophr. Res. 2003, 63, 197.
62. Robertson, D. W.; Annu. Rep. Med. Chem. 1998, 33, 1.

63. Phillips, S. T.; Paulis, T.; Baron, B. M.; Siegel, B. W.; Seeman, P.; van Tol, H. H.; Guan, H. C.; Smith, H. E.; J. Med. Chem. 1994, 37, 2686.

64. Phillips, S. T.; Paulis, S. T.; Neergaard, J. R.; Baron, B. M.; Siegel, B. W.; Seeman, P.; van Tol, H. H. M.; Guan, H. C.; Smith, H. E.; J. Med. Chem. 1995, 38, 708 .

65. Liégeois, J. F.; Rogister, F. A.; Bruhwyler, J.; Damas, J.; Nguyen, T. P.; Inarejos, M. O.; Chleide, E. M. G.; Mercier, M. G. A.; Delarge, J. E.; J. Med. Chem. 1994, 37, 519.

66. Thurkauf, A.; Yuan, J.; Chen, X.; He, X. S.; Wasley, J. W. F.; Hutchison, A.; Woodruff, K. H.; Meade, R.; Hoffman, D. C.; Donovan, H.; JonesHertzog, D. K.; J. Med. Chem. 1997, 40, 1.

67. Tallman, J. F.; Primus, R. J.; Brodbeck, R.; Cornfield, L.; Meade, R.; Woodruff, K.; Ross, P.; Thurkauf, A.; Gallager, D. W.; J. Pharmacol. Exp. Ther. 1997, 282, 1011.

68. Thurkauf, A.; Chen, X.; US pat. 33.7841998.

69. Menegatti, R.; Dissertação de Mestrado, Universidade Federal do Rio de Janeiro, Brasil, 2001.

70. Menegatti, R.; Macchi Jr., I. L.; Cunha, A. C.; Lima, V. L. E.; Rates, S. M. K.; Pereira, E. F.; Albuquerque, E. X.; Rodrigues, C. R.; Fraga, C. A. M.; Ferreira, V. F.; Barreiro, E. J.; Resumos da $23^{a}$ Reunião Anual da Sociedade Brasileira de Química, Poços de Caldas, Brasil, 2000.

71. Menegatti, R.; Cunha, A. C.; Fraga, C. A. M.; Ferreira, V. F.; Barreiro, E. J.; Resumos da $24^{a}$ Reunião Anual da Sociedade Brasileira de Química, Poços de Caldas, Brasil, 2001.

72. Hansch, C.; Taft, R. W.; Chem. Rev. 1991, 91, 165.

73. Menegatti, R.; Cunha, A. C.; Ferreira, V. F.; Pereira, E. F. R.; El-Nabawi, A.; Eldefrawi, A. T.; Albuquerque, E. X.; Neves, G.; Rates, S. M. K.; Fraga, C. A. M.; Barreiro, E. J.; Bioorg. Med. Chem. 2003, 11, 4807.

74. Neves, G.; Fenner, R.; Heckler, A. P.; Viana, A. F.; Tasso, L.; Menegatti, R.; Fraga, C. A. M.; Barreiro, E. J.; Dalla-Costa, T.; Rates, S. M. K.; Braz. J. Med. Biol. Res. 2003, 36, 625 .

75. Teixeira, S.; Dicionário Médico Stedman, Ed. Guanabara Koogan: Rio de Janeiro, 1979.

76. Kuby, J.; Immunology, $3^{\text {th }}$ ed., W. H. Freeman: New York, 1997.

77. Abbas, A.; Lichtman, A.; Pober, J.; Cellular \& Molecular Immunology, $4^{\text {th }}$ ed., W. B. Saunders Company: New York, 2000. 